\title{
ISBT 128: a global information standard
}

\author{
Pat Distler
}

Received: 13 April 2010/ Accepted: 6 July 2010/Published online: 21 July 2010

(C) The Author(s) 2010. This article is published with open access at Springerlink.com

\begin{abstract}
ISBT 128 is the global standard for the identification, labeling and information transfer of human blood, cell, tissue and organ products across international borders and disparate health care systems. The system has been designed and perfected over almost two decades to ensure accuracy, safety and efficiency for the benefit of donors, patients and health care workers worldwide. The use of the ISBT 128 standard has grown steadily since a blood bank in Estonia first implemented it in 1997. Today, more than 3,500 facility identifiers for the use of ISBT 128 have been assigned to organizations in 67 countries on six continents. The standard has been accepted by a variety of international standard setting organizations and government regulators. It is managed by ICCBBA, a not-for-profit organization based in the USA that is governed by an international volunteer board of directors. Members of the Board of Directors represent the fields of practice affected by the standard. Advisory groups comprising international experts guide the ongoing development of the ISBT 128 standard to ensure it continues to meet the needs of its users. While there is a cost associated with the implementation and use of the standard, the clear benefits in terms of improved patient safety and ability to meet regulatory traceability requirements justify the costs.
\end{abstract}

P. Distler $(\bowtie)$

ICCBBA, PO Box 11309, San Bernardino, CA, USA

e-mail: pat.distler@iccbba.org
Keywords ISBT $128 \cdot$ Information standard · International standardization - Human tissue labeling $\cdot$ Traceability $\cdot$ ICCBBA

ISBT 128 is the international standard for the transfer of information associated with transplantation and transfusion. It provides:

- a globally unique donation numbering system

- internationally standardized product codes

- standard data structures for bar coding and electronic data interchange

- standardized labeling

ISBT 128 is a standard; no data related to blood, cellular therapy or tissue donations (apart from details of facilities licensed to use the standard) are maintained by ICCBBA, the organization that maintains the standard.

The name of the standard reflects its origins. A working party of the International Society of Blood Transfusion (ISBT) initially developed the standard. Code 128 was the linear bar code symbology chosen for use with the new standard.

\section{Why standardize?}

The international movement of cell and tissue products is now commonplace. Such movement, without associated standards for identification, 
labeling and information transfer, carries risks which increase workload, compromise traceability, and can lead to serious and potentially fatal patient harm. Without globally unique donation identification and common terminology there is the risk of duplication of identifiers and misidentification of products resulting in the wrong graft being implanted. To overcome this, importers may re-number and re-label imported products; however, this is a process which is time consuming and error prone. In addition, re-numbering makes the traceability path more complex and less reliable. The use of bar coding and computer control is a well recognized means of reducing manual transcription and identification errors, but without international standardization of the bar code representation of critical information, these safety benefits are not available for imported products.

Global standardization of coding and labeling is primarily a patient safety initiative. It permits the international movement of tissues and cells in a manner that eliminates the need for re-numbering, ensures common understanding of product descriptions, and supports computer control to reduce error. It also helps to provide a more robust traceability path and supports rapid alerts in the situation of adverse events requiring product recall.

Since standardization and bar coding have many advantages, it is not surprising that use of ISBT 128 has grown steadily over the years. The need for international standardization is particularly important for cellular therapy and tissue products since there is a high likelihood that these products will be shipped across international borders. The World Marrow Donor Association (2008) indicated that $43.8 \%$ of stem cell donations intended for unrelated recipients were shipped internationally in 2008 and the percent of international shipments has shown an upward climb since 2002.

Recognizing this international transfer of biological products, a WHO (2006) report stated "As this globalization of cells and tissue transplantation develops, the need for common product names and definitions and for unique product identification becomes essential." The commentary of WHO (2008) Guiding Principle 10 states: "Internationally agreed means of coding to identify tissues and cells used in transplantation are essential for full traceability."
A single coding system for blood, cells, tissues and organs is also advantageous as noted in a European Committee for Standardization report (CEN Workshop Agreement, CWA 15849, 2008):

A donor could have a varied donation history, or a single donation event could result in donated material falling under multiple legislation sectors. For instance, a deceased donor could donate organs, tissues and cells in a single donation event. This could be extended to other legislated sectors such as tissue engineering, utilization of embryonic stem cell lines and other regenerative medicine uses.

In the future it is feasible that with technological advances in regenerative medicine that the interfaces between blood, tissues, cells and organs may become less defined.

It is similarly feasible that the legislative framework may have to change to reflect changes in what are now separate sectors governed by discrete pieces of legislation. It is conceivable that the legislative structure may evolve to an umbrella framework in the future. For these reasons it would be useful if the coding system for all sectors had a common background.

Because ISBT 128 provides for coding of blood, cellular therapy and tissue products, and will be extended to include organs, it is an ideal standard to enable facilities to achieve this goal.

Standardization with ISBT 128:

- facilitates international shipment of products because bar codes have the same meaning globally eliminating language barriers

- improves traceability because assigning globally unique identifiers eliminates the need to renumber units when products are received from outside a local area

- improves safety because the receiving facility can understand detailed product characteristics regardless of the language on the label

- reduces costs because software developers do not have to customize their products for each facility

- facilitates movement into newer technology data transfer mechanisms such as two dimensional bar codes and radio frequency identification (RFID) tags 
Bar coding:

- improves safety and traceability by eliminating error-prone keyboard entry of product information

- improves efficiency by allowing scanned entry of products

\section{The beginning}

An early stimulus for ISBT 128 was the 1990-1991 Persian Gulf War when the military received blood from different countries. They found duplication in "unique" identifiers as well as difficulty in reading labels with different languages. Bar codes were frequently present, but could not be interpreted because a given bar code could have different meanings depending on the source of the blood. The US Department of Defense provided a report to the Blood Products Advisory Committee (1997) that stated, "In Desert Shield/Desert Storm the U.S. military contracted with numerous civilian blood suppliers to ship blood to the Persian Gulf. In theatre operations the military found thousands of labeling mistakes. These included: bar code substitution errors; absence or use of un-standardized donation identification start codes; improper or incorrect start codes in FDA registration number; general noncompliance with the 1985 labeling guidelines; and duplication of donation numbers. All of this resulted in misidentification of units, requiring manual data entry and unit renumbering, and increased opportunity for undetected error, and a decrease in productivity." It became apparent that blood was an international resource and there was a desperate need for a globally standardized system of coding critical information.

As a result, the International Society of Blood Transfusion (ISBT) charged its Working Party on Automation and Data Processing (subsequently renamed the Working Party on Information Technology) with creating a standardized means of labeling blood products so that identifiers were globally unique and bar codes (as well as other means of electronic information transfer) would have the same meaning internationally. The first version of the standard they produced was formally approved by the ISBT in 1994.
Almost immediately, tissue and cellular therapy organizations recognized the applicability of the new standard to their work. The Carolinas Cord Blood Bank, Duke University began using ISBT 128 for their products in 1997. The Tissue Services Department of the National Blood Service in the United Kingdom started using ISBT 128 donation identification numbers in 1997, and fully implemented ISBT 128 for tissues in 2003. Following the lead of these organizations, other cellular therapy and tissue facilities worldwide adopted ISBT 128 for labeling and coding of their products.

\section{ICCBBA}

The ISBT Working Party recognized that a mechanism would be required by which the standard could be maintained and developed to meet future needs of the transfusion community. ISBT, in collaboration with the AABB and American Red Cross, agreed to form the International Council for Commonality in Blood Bank Automation (ICCBBA) to manage and develop the standard, and in 1995, ICCBBA was incorporated as a not-for-profit organization in the USA.

ICCBBA is governed by an international volunteer board of directors comprising leaders in the fields of blood, cellular therapy and tissue banking. The Board of Directors meets regularly through conference calls and an annual face-to-face meeting.

ICCBBA is a tax exempt, nonprofit organization as described in Section 501 (c) (3) of the US Internal Revenue Code (Internal Revenue Service 2010). These regulations stipulate that the organization cannot be organized or operated for the benefit of private interests, and no part of the organization's net earnings may inure to the benefit of any private shareholder or individual (IRS.gov 2010). Within its Articles of Association, ICCBBA is required to be organized and operated exclusively for charitable, scientific and educational purposes.

To ensure openness, ICCBBA publishes an Annual Report on its website (www.iccbba.org) that is available to the public. The report discloses ICCBBA's income and expenditures, as well as its balance sheet, and summarizes activities for the year. From the most recent report (ICCBBA 2008), it can be seen that ICCBBA is an efficient organization that 
operates with a small staff and has modest income and expenditures.

\section{The people behind the process}

In its role of managing the ISBT 128 standard, ICCBBA involves international experts in blood, cellular therapy and tissue banking. These experts are organized into Technical Advisory Groups (TAGs) that meet regularly (both face-to-face and through conference calls) to further develop and expand the ISBT 128 standard ensuring that it continues to meet the needs of its users. The vital role of these groups cannot be overemphasized. It is only through the involvement of such expert panels that ICCBBA can be assured it has the knowledge base to anticipate the needs of its users in fields where change is constant. More than 150 experts participate in the ICCBBA TAGs.

There are currently seven TAGs, as described in Table 1. In addition to the membership described in the table, each group may also invite liaisons from professional associations and regulatory agencies to attend its meetings. In order to make the process transparent, other interested persons may attend meetings as observers.

The output of the TAGs is reviewed by an Editorial Board, comprising professionals with both expertise in their fields and experience with ISBT 128 to ensure consistency, accuracy and practicality.

Finally, a small staff of eight people manages the practical aspects of the standard ensuring such things as: documents supporting the standard are written and updated regularly, databases are updated frequently, the communication link to its users (the ICCBBA website) is well-maintained and ICCBBA itself is managed in a stable and professional manner. A full time, dedicated staff ensures that the needs of users are always a priority.

\section{Globally unique identifiers}

A key benefit of ISBT 128 is the assignment of identifiers to products that are unique globally for 100 years. Each identifier (Donation Identification Number or DIN) has three parts: (1) a five-character Facility Identification Number (FIN) assigned by
ICCBBA, (2) a two-character year and (3) a sixcharacter serial number assigned by the facility. (See Fig. 1). These globally unique identifiers eliminate the need to renumber products and thereby simplify and strengthen the traceability process.

The name "Facility Identification Number (FIN)" implies the identifier is assigned to a facility, and in fact this is the most common situation. However, there is flexibility in how the FINs may be assigned. ICCBBA can also assign these identifiers to other organizations such as a regional or national organization, a national health authority or a registry. These organizations can, in turn, manage donation identification numbers.

If there are multiple formats for donation identification numbers, computer systems have to allow a very large field size to accommodate all possible numbers. Moreover, systems cannot be programmed to recognize improperly entered numbers (e.g., ones with too many or too few characters). If all biological products a facility receives have a single, standardized format, computer software may be written to ensure the proper number of characters are entered similarly to the way in which software programs recognize if an email address is not entered in the correct format. While it is hoped that identification numbers would always be scanned into a computer system, this is not always going to be the case. If the entry of the number is made through a keyboard, it becomes even more important for the computer system to recognize if a number was entered in the wrong format.

When manual systems are used, it is still important to have a standard format so manual worksheets can be designed to prompt the user to record the correct number of characters.

As noted above, the importance of internationally standardized unique identifiers was recognized in both a WHO report (2006) and the US Department of Defense report to the Blood Products Advisory Committee (1997).

\section{Product coding}

The ISBT 128 product description code database contains more than 7,000 product description codes. Each product description (e.g., Hematopoietic Progenitor Cell collected by apheresis, using citrate as an 
Table 1 ICCBBA technical advisory groups

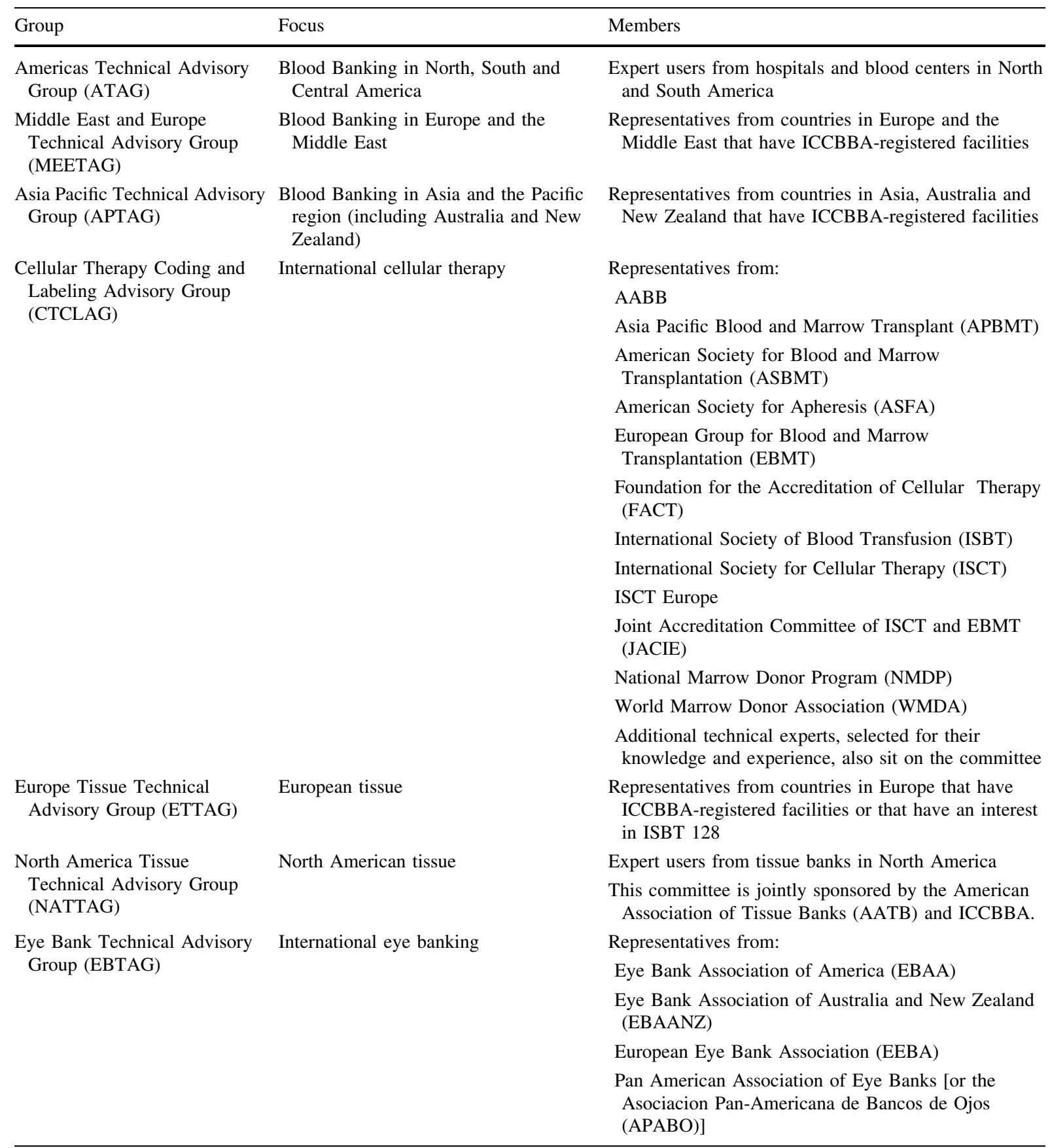

anticoagulant and stored at room temperature) is assigned a five-character product description code. There are three additional characters in each product code: For cells and blood, there is a one-character donation type (e.g., allogeneic or autologous) code followed by a two-character division code. For tissues, there is a three-character division code (See Fig. 2).

The five-character product descriptions and codes are maintained in a database (see Table 2 for an excerpt) on the ICCBBA website and made available to ICCBBA-licensed facilities. 


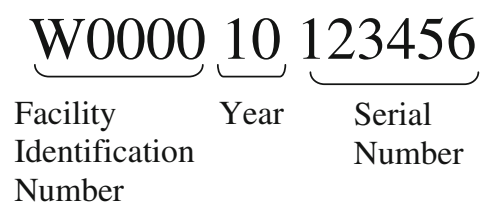

Fig. 1 Donation identification number

Fig. 2 Tissue product code

$\underbrace{\mathrm{T} 0122}_{\begin{array}{l}\text { Product } \\ \text { Description } \\ \text { Code }\end{array}} \underbrace{000}_{\text {Divisions }}$

One of the attractive features of the ISBT 128 standard is its flexibility. The level of detail that is encoded into the electronically readable information can vary. For example, for blood products each anticoagulant (CPD, CPDA-1, CP2D, ACD-A, ACD$\mathrm{B}$, Sodium Citrate or heparin) may be encoded into electronically readable information. However it is also possible to encode a blood product without specifying the anticoagulant. This level of flexibility has led to over 6,700 blood product description codes. However, the Cellular Therapy Coding and Labeling Advisory Group (CTCLAG) chose to encode much less detail into product description codes for cellular therapy products. Here, simply encoding citrate and/or heparin as the anticoagulant was considered an adequate level of detail for electronic communication. The specific anticoagulant may be detailed in other documentation accompanying the product, but is not communicated electronically. This has led to far fewer cellular therapy product description codes and hence less complexity.

Within tissue banking, the Europe Tissue Technical Advisory Group (ETTAG) and the North America Tissue Technical Advisory Group (NATTAG) are currently determining the level of detail needed for tissue products in the future. The international Eye Bank Technical Advisory Group is also in the process of determining the level of detail appropriate for electronic communication.

Within the constraints determined by the advisory groups, the standard allows facilities to select the product description codes that describe their products at the level of detail most appropriate for the users of their products.

ICCBBA-licensed facilities may request new codes whenever they are needed through a simple on-line request form. If such codes do not require any new terminology, they are generally available within 4-6 weeks. If new terminology is needed, the request is reviewed by the appropriate technical advisory group to ensure consensus for the terminology chosen and may take a little longer.

\section{Managing change to the standard}

Changes to the standard are required as new products are developed. Changes are also frequently needed when the first facility within a country adopts the standard. Such changes are carefully managed through a transparent proposal process. Any user can suggest changes. Suggestions are captured into formal proposals which are reviewed by the TAG(s) with the appropriate expertise. If approved by the TAGs, the proposals are reviewed by the Editorial Board and staff for consistency with the ISBT 128 standard and for backward compatibility. Once final approval is obtained, changes are published in appropriate documents and made available to users.

\section{Worldwide usage of ISBT 128}

As of January 1, 2010, more than 3,500 facility identifiers for the use of ISBT 128 had been assigned to organizations in 67 countries (see Table 3) on six continents. Not all facilities that are registered with ICCBBA will have implemented ISBT 128 and registration may be by blood, cellular therapy and/ or tissue facilities within a country.

Given the frequency with which cellular therapy products are shipped across national borders, standard setting organizations (AABB, FACT and JACIE) were quick to see the benefit of standardized terminology. These cellular therapy standards organizations now require that ISBT 128 terminology be used to label products (AABB 2009) (FACT/JACIE 2008). This requirement came about very quickly once CTCLAG reached consensus on terminology (Ashford et al. 2007a, c, f) and provided guidance for implementation (Ashford et al. 2007b, d, e). Long term, it is expected that these organizations will require full ISBT 128 labeling.

Representatives from international eye banking associations and other interested parties have begun 
Table 2 Excerpt from ICCBBA product code description database

\begin{tabular}{lll}
\hline Product description code & Proddescription & Code date \\
\hline T0122 & Cryopreserved VALVE, AORTIC & 14 Feb 2001 \\
\hline
\end{tabular}

Table 3 Countries with ICCBBA-registered facilities

\begin{tabular}{lll}
\hline Algeria & Germany & Poland \\
Argentina & Greece & Portugal \\
Australia & Honduras & Qatar \\
Austria & Hungary & Republic of China \\
Belarus & Iceland & Russian Federation \\
Belgium & India & Saudi Arabia \\
Bosnia-Herzegovina & Iran & Serbia \\
Botswana & Ireland & Singapore \\
Brazil & Israel & Slovenia \\
Canada & Italy & South Africa \\
China & Japan & South Korea \\
Columbia & Jordan & Spain \\
Cote d'Ivoire & Kazakhstan & Sultanate of Oman \\
Croatia & Kuwait & Sweden \\
Cyprus & Latvia & Switzerland \\
Czech Republic & Lithuania & Thailand \\
Denmark & Malaysia & The Netherlands \\
Dominican Republic & Mexico & Turkey \\
Egypt & Moldova & United Arab Emirates \\
Estonia & Nigeria & United Kingdom \\
Ethiopia & Norway & United States of America \\
Finland & Pakistan & Vietnam \\
France & & \\
\hline & & \\
\hline
\end{tabular}

meeting recently to extend ISBT 128 coding and labeling to their products. As indicated in Table 1, membership in this advisory group reflects a global interest in use of the ISBT 128 standard for ocular tissue.

\section{Information access}

ICCBBA makes available to the public most of its documents through its website (www.iccbba.org). These publicly available documents include:

- ISBT 128 Standard Technical Specification (the primary document for describing the standard)

- Standard Terminology for Blood, Cellular Therapy and Tissue Product Descriptions
- Technical Bulletins of general interest

Additionally, educational and introductory documents are available to all who are interested. The ICCBBA website provides a vast amount of information and is a primary resource in implementing ISBT 128.

Databases (product description codes and facilities), as well as technical documents specific to the implementation of the standard, are available on the ICCBBA website to users from facilities that are registered and licensed with ICCBBA and that have requested a password to access this information. Both the facility and product description code databases are updated approximately 10 times per year as new product description codes and facilities are added.

\section{Fees}

To best meet the needs of its users, the ISBT 128 standard must be maintained in a manner that is stable, flexible and responsive. It must be professionally managed to ensure these needs are met. As is the case for all services of high quality, there is an associated cost.

ICCBBA charges a fee, which is published on its website, for services that include the use of the ISBT 128 Standard and its supporting databases, access to the full documentation set, provision of globally unique facility identifiers, and helpdesk technical support. The annual license fee is established by the ICCBBA Board of Directors taking a number of factors into consideration. Chief among these is funding the annual cost of operations for supporting, maintaining and administering the ongoing development of the standard for the benefit of all users. Additional factors include the type of licensee organization and the location of the organization. Fees are reduced for countries in low and medium development areas as defined by the U.N.'s Human Development Index (HDI).

ICCBBA operates a highly flexible billing system and can group facilities together for billing purposes. 
This allows various funding models to be supported including payment by individual facility, payment by a single administrative source for multiple facilities (such as a Red Cross administrative center paying for all Red Cross facilities in a country), and payment by a national authority for all facilities in the country.

\section{Future}

The future of ISBT 128 will reflect the future of the facilities it serves. Facilities in additional countries will adopt ISBT 128 and have special needs. New products will be developed. Especially in the area of cellular therapy, some of these new products will be challenging to define. Regenerative medicine will blur the lines between cellular and tissue products. ISBT 128 must meet these challenges and provide the tools for coding and labeling a wide variety of new biological products in a timely manner.

New TAGs with expertise in a variety of fields will likely be needed. For example, Reproductive Medicine is a field where ICCBBA will likely need additional expertise to ensure that ISBT 128 meets the needs of coding and labeling these very specialized products. Organ transplant is clearly another area where ISBT 128 can be of benefit and expert panels will need to be organized and supported.

With each new country that adopts ISBT 128 , the standard will also have to demonstrate its flexibility to be compatible with a wide variety of national regulations for the labeling of biological products.

As with all things in life, success is about balance. The future success of the ISBT 128 standard rests on its on-going ability to achieve balance in-

- achieving standardization that ensures products can cross international borders with labeling that can be read and interpreted as intended while providing the flexibility to meet the global needs for different languages and regulations

- attracting people with new expertise into its TAGs while retaining professionals experienced with the use ISBT 128

- encouraging creativity to meet future needs while remembering lessons learned

- bringing in new fields such as organ transplant while meeting the needs of fields already using the standard
- being responsive to requests for change while giving careful consideration to ensure changes are wise

- offering high value for fees charged while having adequate resources to meet the expanding needs of high growth fields

Work on the ISBT 128 standard began almost two decades ago. Since that time, many countries have implemented it and shown that the standard is capable of meeting the changing needs for coding and labeling of biologics over the long term. In doing so, the ISBT 128 standard has proven it is capable of achieving the necessary balance to ensure continued stability and growth.

Open Access This article is distributed under the terms of the Creative Commons Attribution Noncommercial License which permits any noncommercial use, distribution, and reproduction in any medium, provided the original author(s) and source are credited.

\section{References}

AABB (2009) Standards for cellular therapy product services, 4 th edn. AABB, Bethesda

Ashford P, Distler P, Gee A, Lankester A, Larsson S, Feller I, Loper K, Pamphilon D, Poston L, Rabe F, SlaperCortenbach I, Szczepiorkowski Z, Warkentin P (2007a) Terminology and labeling of cellular products: 1. Standards. Bone Marrow Transplant 40(11):1075-1083. doi:10.1038/sj.bmt. 1705858

Ashford P, Distler P, Gee A, Lankester A, Larsson S, Feller I, Loper K, Pamphilon D, Poston L, Rabe F, Slaper-Cortenbach I, Szczepiorkowski Z, Warkentin P (2007b) Terminology and labeling of cellular products 2: implementation plan. Bone Marrow Transplant 40(11):1085-1090. doi:10.1038/sj.bmt.1705859

Ashford P, Distler P, Gee A, Lankester A, Larsson S, Feller I, Loper K, Pamphilon D, Poston L, Rabe F, Slaper-Cortenbach I, Szczepiorkowski Z, Warkentin P (2007c) Standards for the terminology and labeling of cellular therapy products. Transfusion 47(7):1319-1327. doi: 10.1111/j.1537-2995.2007.01389.x

Ashford P, Distler P, Gee A, Lankester A, Larsson S, Feller I, Loper K, Pamphilon D, Poston L, Rabe F, SlaperCortenbach I, Szczepiorkowski Z, Warkentin P (2007d) ISBT 128 implementation plan for cellular therapy products. Transfusion 47(7):1312-1318. doi:10.1111/j.15372995.2007.01390.x

Ashford P, Distler P, Gee A, Lankester A, Larsson S, Feller I, Loper K, Pamphilon D, Poston L, Rabe F, SlaperCortenbach I, Szczepiorkowski Z, Warkentin P (2007e) ISBT 128 implementation plan for cellular therapy products. J Clin Apher 22(5):258-264. doi:10.1002/jca.20146 
Ashford P, Distler P, Gee A, Lankester A, Larsson S, Feller I, Loper K, Pamphilon D, Poston L, Rabe F, Slaper-Cortenbach I, Szczepiorkowski Z, Warkentin P (2007f) Standards for the terminology and labeling of cellular therapy products. J Clin Apher 22(5):249-257. doi:10.1002/jca.20145

Blood Products Advisory Committee (1997) Center for biologics and evaluation. Proceedings of BPAC meeting, June 20, 1997. http://www.fda.gov/ohrms/dockets/ac/97/transcpt/ 3304t2.rtf. Accessed 4 March 2010

CEN Workshop Agreement (2008) CWA 15849, CEN Workshop Agreement on 'Coding of information and traceability of human tissues and cells' European committee for standardization (CEN) (2008). ftp://cenftp1.cenorm. be/PUBLIC/CWAs/e-Europe/Tissues_cells/CWA158492008-publishedtext.pdf). Accessed 4 March 2010

FACT/JACIE (2008) International standards for cellular therapy product collection, processing, and administration, 4 th edn. Foundation for the accreditation of cellular therapy and joint accreditation committee-ISCT and EMBT (JACIE). http://www.jacie.org/portal/jacie/standards/Controller; jsessionid=5D20E12AB70386A10BF6F8E758772111? mvchandler $=$ portals \&action $=$ show-screen $\&$ screen $=$ work space $\&$ idSection=1268. Accessed 4 March 2010
IRS.gov (2010) http://www.irs.gov/charities/charitable/article/ 0,id=123297,00.html. Accessed 4 March 2010

ICCBBA (2008) Annual Report. http://www.iccbba.org/info_ annualreport.pdf). Accessed 24 March 2010

Internal Revenue Service (2010) http://www.irs.gov/charities/ charitable/article/0,id=96099,00.html. Accessed 4 March 2010

WHO (2006) Second global consultation on regulatory requirements for human cells and tissues for transplantation: towards global harmonization through graduated standards, WHO Geneva, 7-9 June 2006 Report World Health Organization. http://www.who.int/transplantation/ 2dHTTGHreport.pdf. Accessed 4 March 2010

WHO (2008) Guiding principles on human cell, tissue and organ transplantation-2008. World Health Organization. http://www.searo.who.int/LinkFiles/BCT_WHO_guiding_ principles_organ_transplantation.pdf. Accessed 4 March 2010

World Marrow Donor Association (2008) Stem cell donor registries annual report 2008 